\title{
BMJ Open BlueHealth: a study programme protocol for mapping and quantifying the potential benefits to public health and well-being from Europe's blue spaces
}

\author{
James Grellier, ${ }^{1,2}$ Mathew P White, ${ }^{1,3}$ Maria Albin,, ${ }^{4,5}$ Simon Bell,, ${ }^{6,7}$ Lewis R Elliott, ${ }^{1,3}$ \\ Mireia Gascón, ${ }^{8,9,10,11}$ Silvio Gualdi, ${ }^{12}$ Laura Mancini, ${ }^{13}$ \\ Mark J Nieuwenhuijsen, ${ }^{8,9,10,11}$ Denis A Sarigiannis, ${ }^{14}$ Matilda van den Bosch, ${ }^{15,16,17}$ \\ Tanja Wolf, ${ }^{17}$ Susanne Wuijts, ${ }^{18}$ Lora E Fleming $^{1}$
}

To cite: Grellier J, White MP, Albin M, et al. BlueHealth: a study programme protocol for mapping and quantifying the potential benefits to public health and well-being from Europe's blue spaces. BMJ Open 2017;7:e016188. doi:10.1136/ bmjopen-2017-016188

- Prepublication history for this paper is available online. To view these files please visit the journal online (http://dx.doi org/10.1136/bmjopen-2017016188).

Received 1 February 2017 Revised 23 March 2017 Accepted 31 March 2017

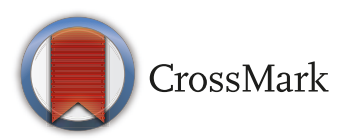

For numbered affiliations see end of article.

Correspondence to

Dr James Grellier;

j.grellier@exeter.ac.uk

\section{ABSTRACT}

Introduction Proximity and access to water have long been central to human culture and accordingly deliver countless societal benefits. Over 200 million people live on Europe's coastline, and aquatic environments are the top recreational destination in the region. In terms of public health, interactions with 'blue space' (eg, coasts, rivers, lakes) are often considered solely in terms of risk (eg, drowning, microbial pollution). Exposure to blue space can, however, promote health and well-being and prevent disease, although underlying mechanisms are poorly understood.

Aims and methods The BlueHealth project aims to understand the relationships between exposure to blue space and health and well-being, to map and quantify the public health impacts of changes to both natural blue spaces and associated urban infrastructure in Europe, and to provide evidence-based information to policymakers on how to maximise health benefits associated with interventions in and around aquatic environments. To achieve these aims, an evidence base will be created through systematic reviews, analyses of secondary data sets and analyses of new data collected through a bespoke international survey and a wide range of community-level interventions. We will also explore how to deliver the benefits associated with blue spaces to those without direct access through the use of virtual reality. Scenarios will be developed that allow the evaluation of health impacts in plausible future societal contexts and changing environments. BlueHealth will develop key inputs into policymaking and land/water-use planning towards more salutogenic and sustainable uses of blue space, particularly in urban areas.

Ethics and dissemination Throughout the BlueHealth project, ethics review and approval are obtained for all relevant aspects of the study by the local ethics committees prior to any work being initiated and an ethics expert has been appointed to the project advisory board. So far, ethical approval has been obtained for the BlueHealth International Survey and for communitylevel interventions taking place in Spain, Italy and the
Strengths and limitations of this study

- BlueHealth (www.bluehealth2020.eu) is the first study programme to explore systematically the benefits to human health and well-being associated with interacting with blue space across Europe.

- BlueHealth uses a variety of methods drawn from several disciplines to examine possible complex mechanisms underlying relationships between blue spaces and public health.

- The project uses novel tools and methods to evaluate the changing characteristics and states of blue spaces associated with interventions made to urban infrastructure as well as with climate and other environmental change.

- Although BlueHealth is looking at some risks associated with blue spaces, the project is chiefly focused on benefits to health; findings will therefore need to be integrated with existing and ongoing research relating to risks in order to fully understand potential trade-offs.

- Although the breadth of approaches and methods used in BlueHealth in different geopolitical and demographic contexts ensures broad applicability of the findings in decision-making processes in Europe, it is uncertain how the project outputs might transfer to low- and middle-income countries.

UK. Engagement of stakeholders, including the public, involves citizens in many aspects of the project. Results of all individual studies within the BlueHealth project will be published with open access. After full anonymisation and application of any measures necessary to prevent disclosure, data generated in the project will be deposited into open data repositories of the partner institutions, in line with a formal data management plan. Other knowledge and tools developed in the project will be made available via the project website (www.bluehealth2020. eu). Project results will ultimately provide key inputs to planning and policy relating to blue space, further 
stimulating the integration of environmental and health considerations into decision-making, such that blue infrastructure is developed across Europe with both public health and the environment in mind.

\section{INTRODUCTION}

Proximity and access to water have been central to human settlement throughout history. ${ }^{1}$ As well as providing sources of drinking water and food, water and the 'blue space' around it facilitate transport, commerce and power generation, and afford recreation and tourism. Consequently, many of the world's largest cities are situated by water, and an extensive network of urban 'blue infrastructure' (eg, canals, harbour walls) has been developed to secure the benefits and mitigate concomitant risks. Cities globally are undergoing rapid change. Urban coastal populations are growing, ${ }^{2}$ and many cities have seen extensive postindustrial transformation of canals and riversides, ${ }^{3-5}$ docks, ${ }^{6-8}$ ports, ${ }^{9}{ }^{10}$ harbours ${ }^{11-14}$ and other types of waterfront, ${ }^{15}{ }^{16}$ following changes in global trading patterns. Although environmental, social and economic impacts of waterside regeneration have been explored (eg, refs. ${ }^{1718}$ ), its potential implications in terms of public health and well-being have only recently been scientifically investigated (eg, ref. $\left.{ }^{19-22}\right)$. This is in contrast to green spaces (such as urban parks, woodlands and street trees), where a significant evidence base supports their role in health protection and disease prevention. ${ }^{23}$ Twentieth-century trends in population growth and urbanisation in coastal areas globally are forecast to continue through this century. ${ }^{2}$ Since increasingly large populations exploit or otherwise experience bodies of water through work and recreation in urban settings, human contact with blue environments is increasingly mediated by blue infrastructure.

The scientific understanding of health hazards and risks associated with water is well-developed. For example, certain aquatic habitats support vectors of diseases (such as malaria, yellow fever and dengue ${ }^{24-26}$ ) and can be sources of human exposure both to microbes responsible for infectious diseases (such as cholera ${ }^{27}$ and typhoid ${ }^{28}$ ) and to a range of chemical pollutants. ${ }^{29}$ Water is a hazard in itself: drowning is the third most common cause of unintentional death globally ${ }^{30}$; various complex health risks may result from flooding and its aftermath. ${ }^{31-33}$ Activities carried out recreationally in blue spaces are associated with health impacts unrelated to water itself, such as increased risk of sunburn and skin cancer from sunbathing. ${ }^{34}$ Many of these risks are amplified by the effects of environmental degradation and climate change. Far less is known about the public health and individual well-being benefits of interactions with blue spaces and infrastructures built in, on and around them.

Epidemiological evidence suggests that people living near-or having views of-the coast are generally healthier, ${ }^{21} 35$ experience fewer symptoms of mental distress ${ }^{3637}$ and are more satisfied with their lives ${ }^{38}$ than those living inland. Longitudinal evidence suggests that mental and physical health are typically better in people for periods spent living closer to the sea. ${ }^{39}$ The positive effects of living near the coast seem particularly pronounced for those with the highest levels of socioeconomic deprivation, ${ }^{21}$ suggesting less health inequalities in such locations. Little is known about whether these effects are specific to coastal environments or if other blue spaces (eg, rivers, lakes, canals, etc) confer similar benefits on health. Preliminary evidence suggests that several pathways may account for the positive relationship between health and well-being and exposure to blue space. First, people feel happier ${ }^{38}$ and less stressed $^{41}$ in blue space settings than in other outdoor locations (replicated under laboratory conditions ${ }^{42}$ ). Second, those living near blue spaces spend more time in them than those living further away. ${ }^{43}$ Third, coastal inhabitants are more likely to meet national guidelines for physical activity than those inland. ${ }^{44}$ Also, blue spaces are seen as particularly important places to participate in positive social interactions with friends and family ${ }^{45}$ and are more widely used for health and well-being purposes than green spaces. ${ }^{2146}$ Lastly, water bodies can contribute to mitigating the urban heat island effect, ${ }^{47}$ which is especially important as average summer temperatures rise and heat-related morbidity and mortality increase. ${ }^{48}$

As urban green spaces are increasingly encroached upon by construction, ${ }^{49}$ and as populations near large water bodies increase in size, urban blue spaces may become increasingly important sites for recreation. The incorporation of evidence on the salutogenic effects of certain exposures to blue spaces into urban planning and development of urban infrastructure could contribute to tackling key public health challenges, ${ }^{50} 51$ from reducing the incidence of non-communicable diseases associated with sedentary lifestyles and stress to reducing morbidity and mortality related to increasing temperatures. ${ }^{52-54}$

Research on relationships between exposure to blue spaces and health is less well-established than that conducted on green spaces and health, ${ }^{55}$ and particularly little evidence exists regarding effects of blue spaces other than coastlines. In Europe, research has been conducted in only a few countries and results have been inconclusive, largely due to low statistical power. ${ }^{56}$ The overarching goal of the BlueHealth project (www.bluehealth2020.eu) is to fill these gaps. Over its four-and-a-half-year duration, this pan-European project aims to understand better associations between exposure to blue space and health and well-being through a large-scale systematic programme of interdisciplinary research that investigates exposure to blue space and its effects on health and well-being in various geographical, climatic, socioeconomic and cultural contexts across Europe. Furthermore, it aims to quantify the public health impacts of existing and novel interventions and policy initiatives connected to blue space environments, and will develop tools that support decision-making on future investments in Europe's blue infrastructure with health promotion in mind. 


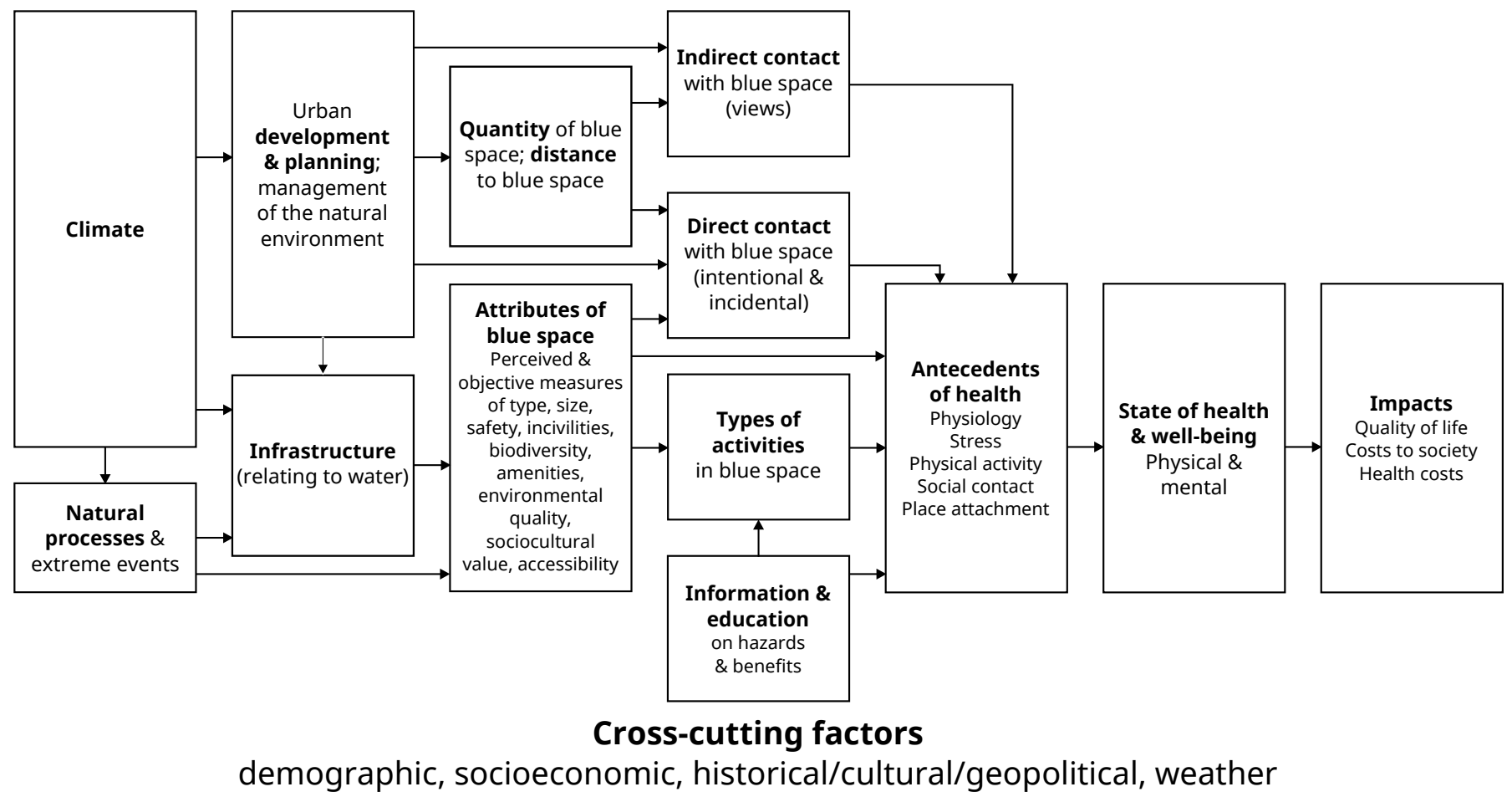

Figure 1 BlueHealth conceptual framework: an influence diagram describing the causal chain between drivers and impacts under investigation in the BlueHealth project.

\section{METHODS AND ANALYSIS}

\section{BlueHealth conceptual model}

Within the scope of BlueHealth we define blue spaces as outdoor environments-either natural or manmadethat prominently feature water and are accessible to humans either proximally (being in, on or near water) or distally/virtually (being able to see, hear or otherwise sense water). We hypothesise that many benefits to health and well-being from exposure to blue space follow pathways similar to those identified for green space (eg, ref. 57-61). We hypothesise that they differ since research suggests that people are particularly motivated to spend time in blue spaces compared with green, grey or mixed blue/green spaces, and that affordances exploited in blue spaces may be particularly beneficial, even relative to green or mixed spaces. ${ }^{41} 6263$ Through an iterative process of literature review and discussion, we created an influence diagram-the BlueHealth conceptual model (figure 1) - that begins to answer the question 'What causal chains link drivers of urban infrastructural change to impacts on public health and well-being?' in terms of what could be feasibly explored within BlueHealth.

The conceptual model posits that changes made to urban infrastructure and planning will be influenced by future changes in climate, particularly extreme events, as well as responding to a number of cross-cutting issues such as demographic, economic, technological and historical/cultural/geopolitical factors (eg, Europe's
Blue Growth agenda $\left.{ }^{64}\right)$. These changes might impact on the amount and relative distribution of blue space 'available' to the public, or on its character. They may change a population's contact (direct and indirect exposure) with blue spaces, as well as types of activities conducted therein. We consider that changes in exposure to blue space will influence the determinants of health, in terms of stress, physical activity, social contact and place attachment, climate change mitigation and adaptation and, subsequently, on the states of health and well-being that impact on quality of life, on healthcare systems and on society at large. We also recognise that these impacts will vary across and within different populations, and across climate zones.

\section{Building an evidence base}

To answer the question posed above, the project will build a robust evidence base on the impacts of exposure to blue space on health and well-being, through reviews of existing evidence, analyses of available secondary data, and collection and analysis of a multitude of novel data sets by way of a pan-European online panel survey, community-level interventions (CLIs) and application of virtual reality (VR).

\section{Reviews}

Despite several extensive reviews of health and (urban) green space (eg, refs. 5961 65-69), we know of only one scoping review examining the relationships between 
health, well-being and blue spaces, ${ }^{20}$ and one review on the health impacts of green and blue space that highlighted the insufficient data available on the association between mental health and blue space. ${ }^{67}$ BlueHealth will build on these preliminary reviews by employing best practice evidence synthesis guidelines to conduct three broader and up-to-date reviews of the literature and international practice.

The first review will provide a systematic synthesis of the evidence on the relationships between urban blue spaces and the benefits to health and well-being, answering the question: 'To what extent, and through what mechanisms, is exposure to urban blue space associated with opportunities for health and well-being promotion and disease prevention?' The results of this review focus the collection of primary and secondary data in the project and guide analytical strategies of them.

The second review will seek to answer the question: 'What facets of urban blue infrastructure design and project implementation best promote health and wellbeing?' This review will examine the effectiveness of plans and, particularly, built environment projects at enhancing public health and well-being. Project documentation, information on planning and implementation processes, and current condition and usage will be evaluated in each case. A set of BlueHealth criteria will be based on the outcomes of this review; subsequently, these can be used to evaluate new policies and plans in terms of their potential impact on public health. Since much of the evidence is documented in unpublished reports and the professional press, the review will focus on those projects which have, for example, won international design competitions or prizes.

The third review will answer the question: 'To what extent, and through what mechanisms, do indoor artificial recreations of blue (and other natural) environments impact on health and well-being?' It will systematically consider effects on health and well-being of blue environments recreated indoors, including the use of aquaria, ${ }^{70}$ photographs and paintings, and VR. The outcomes of this review will enable the focused development of VR studies conducted within BlueHealth.

\section{Secondary data analysis}

Analyses of secondary data will be carried out to further understanding of how blue space affects health and wellbeing. Previous analyses of secondary data have been country-specific and suffered from comparability issues due to differences in exposure assessment, outcome measures, adjustment for confounders and analytical methods. We will conduct coordinated research on key European data sets that contain common health outcomes (eg, GHQ12, ${ }^{71}$ SF-36, ${ }^{72}$ Global Life Satisfaction ${ }^{73}$ ), allowing for consistent operationalisation of exposure to blue space (ie, residential proximity), including the UK Understanding Society survey ( 40000 subjects per 2-year wave), ${ }^{74}$ the Enquesta de Salut de Catalunya ('Health Survey of Catalonia') ( 8000 subjects per 4-year sample) ${ }^{75}$ and the Swedish Skåne Public Health Questionnaire ( 28 000 subjects per 4-year wave ${ }^{76}$ Survey responses will be geocoded as population-weighted centroids of lower layer super output areas (UK) and residential address (Sweden and Catalonia); various metrics of residential proximity to blue space (based on previous research ${ }^{456}$ ) and area-level average exposures will be assigned using the European Environment Agency's Urban Atlas. ${ }^{77}$ Analysis of these data using a common protocol will allow for comparisons of large samples in three European countries.

Primary data collection and analysis

BlueHealth International Survey

A bespoke BlueHealth International Survey (BIS) is being developed to collect primary data on a large sample of the European populations' recreational experiences of blue spaces and reported health and well-being status. The survey will collect large, nationally representative samples of individuals, stratified on age, sex, region and employment status, in 14 European countries (Bulgaria, Czech Republic, Estonia, Finland, France, Germany, Greece, Ireland, Italy, Portugal, Spain, Sweden, the Netherlands, the UK), which represent a range of climatic, geographic and cultural contexts, have coastlines on the Atlantic, the North Sea, the Mediterranean, the Black Sea or the Baltic-or are landlocked-and several feature high numbers of lakes and include Europe's largest rivers. One thousand panel members will be surveyed in each country (except in Bulgaria and Estonia, where 500 individuals will be surveyed). For comparability with existing evidence, questionnaire items have been chiefly drawn from national surveys and European projects..$^{55} 78$ Outcome measures include validated pre-translated health and well-being measures such as the WHO-5 Well-being Index ${ }^{79}$ and items in the European Social Survey. ${ }^{80}$

The BIS will facilitate cross-sectional analyses of nationally representative samples across Europe and will primarily focus on elucidating the potential physical and mental health effects of recreational (as opposed to occupational) experiences in blue spaces. It will also facilitate various economic evaluations. First, a travel-cost method will be used to ascribe monetary values to visits using data collected on distances travelled, time taken and mode of transport used to get from a starting point to different blue space destinations. Second, economic values will be assigned to levels of physical activity undertaken within different blue environments, using existing protocols. ${ }^{81} 82$ Third, a contingent behaviour approach will be used to gauge public reactions to the European Union's (EU's) updated Bathing Water Standards and associated signage, introduced in 2015/2016. Water quality at 15363 designated coastal and 6473 inland bathing water sites across the EU is now scored in terms of a four-point classification, namely excellent, good, sufficient and poor. We will investigate how willingness to visit bathing sites is affected by the classifications and signage, thereby informing us of how bathing water quality may affect recreational choice. 
Table 1 Summary of BlueHealth community-level interventions (CLIs)

\begin{tabular}{|c|c|c|c|c|c|}
\hline Type of CLI & Name & Location & $\begin{array}{l}\text { Nature of } \\
\text { intervention }\end{array}$ & $\begin{array}{l}\text { Evaluation } \\
\text { timing }\end{array}$ & Evaluation tools \\
\hline \multirow[t]{5}{*}{$\begin{array}{l}\text { Environmental } \\
\text { interventions (interventions } \\
\text { made to the environment) }\end{array}$} & $\begin{array}{l}\text { Appia Antica } \\
\text { Park }\end{array}$ & Rome, Italy & $\begin{array}{l}\text { Improve } \\
\text { information on } \\
\text { access to, and } \\
\text { use of, an urban } \\
\text { park }\end{array}$ & $\begin{array}{l}\text { Cross section of } \\
\text { users versus non- } \\
\text { users }\end{array}$ & BCLS, BEAT, BSGIS \\
\hline & $\begin{array}{l}\text { Besòs River } \\
\text { access }\end{array}$ & $\begin{array}{l}\text { Montcada } \\
\text { i Reixac, } \\
\text { Spain }\end{array}$ & $\begin{array}{l}\text { Provision of } \\
\text { access to an } \\
\text { urban riverside } \\
\text { path }\end{array}$ & Pre and post & BEAT, BCLS \\
\hline & $\begin{array}{l}\text { Marazion } \\
\text { dune cycle } \\
\text { path }\end{array}$ & Cornwall, UK & $\begin{array}{l}\text { Urban } \\
\text { acupuncture }\end{array}$ & Pre and post & BSGIS, BEAT, BCLS \\
\hline & Anne Kanal & $\begin{array}{l}\text { Tartu, } \\
\text { Estonia }\end{array}$ & $\begin{array}{l}\text { Urban } \\
\text { acupuncture }\end{array}$ & Pre and post & BSGIS, BEAT, BCLS \\
\hline & $\begin{array}{l}\text { Tallinn urban } \\
\text { shoreline }\end{array}$ & $\begin{array}{l}\text { Tallinn, } \\
\text { Estonia }\end{array}$ & $\begin{array}{l}\text { Urban } \\
\text { acupuncture }\end{array}$ & Pre and post & BSGIS, BEAT, BCLS \\
\hline \multirow{3}{*}{$\begin{array}{l}\text { Behavioural } \\
\text { interventions (interventions } \\
\text { made to population } \\
\text { behaviour) }\end{array}$} & $\begin{array}{l}\text { Walking } \\
\text { office } \\
\text { workers }\end{array}$ & $\begin{array}{l}\text { Barcelona, } \\
\text { Spain }\end{array}$ & Trial & $\begin{array}{l}\text { Walking group } \\
\text { versus control }\end{array}$ & BPAT \\
\hline & $\begin{array}{l}\text { Walking } \\
\text { office } \\
\text { workers }\end{array}$ & $\begin{array}{l}\text { Thessaloniki, } \\
\text { Greece }\end{array}$ & Trial & $\begin{array}{l}\text { Walking group } \\
\text { versus control }\end{array}$ & BPAT \\
\hline & $\begin{array}{l}\text { School } \\
\text { swimming } \\
\text { lessons }\end{array}$ & $\begin{array}{l}\text { Malmö, } \\
\text { Sweden }\end{array}$ & $\begin{array}{l}\text { Observational, } \\
\text { difference in } \\
\text { difference }\end{array}$ & Pre and post & Swimming ability \\
\hline
\end{tabular}

BBAT, BlueHealth Behavioural Assessment Tool; BCLS, BlueHealth Community-Level Survey; BEAT, BlueHealth Environmental Assessment Tool; BPAT, BlueHealth Physiological Assessment Tool; BSGIS, BlueHealth SoftGIS.

\section{Community-level interventions}

At the local scale, we will evaluate impacts on health and well-being of changes to blue infrastructure and recreational behaviour in a range of CLIs. Conducted across eight European countries, these CLIs were selected to encompass a variety of blue spaces (eg, coast, rivers, lakes) and a broad range of demographic, socioeconomic, histor$\mathrm{ical} / \mathrm{cultural} /$ regional and climatic contexts (table 1). Ten CLIs are classed as environmental interventions, wherein a tangible change to an aspect of the (urban) blue infrastructure will take place during the course of the project. The impacts of these interventions on the health and 
well-being of local residents and users will be monitored. In five of these CLIs, the interventions are being made according to existing plans made by third parties. In the other five, we have the opportunity to make novel alterations to the environment to test specific hypotheses. We refer to these as 'urban acupuncture' interventions, ${ }^{83}$ by which we mean relatively small-scale interventions made at underused, inaccessible or negatively perceived sites, that may confer disproportionately large positive impacts on the use or enjoyment of those places by given populations. Each urban acupuncture intervention will be context-specific, and designed, co-created and installed with the cooperation of key stakeholders, including local landscape architects, engineers and planners, and local residents. The economic costs of the interventions will be monitored to enable estimation of the cost-effectiveness of each in increasing salutogenic use of each space. The other three CLIs are classed as behavioural interventions, meaning that they aim to change the way people interact with existing (urban) blue infrastructures. These include promotion of lunchtime walking for office workers in Barcelona (Spain) and Thessaloniki (Greece), and school swimming lessons for children of immigrant families that recently moved to Malmö (Sweden).

Five evaluation tools are being developed to assess aspects the CLIs:

1. The BlueHealth Community Level Survey (BCLS) is a shorter site-specific version of the BIS. It will be used with local communities before and after environmental interventions. The inclusion of items common to the BCLS and BIS allows the integration of findings from CLIs with higher-level data from the same country.

2. The BlueHealth Environmental Assessment Tool (BEAT) will be used in all CLIs to assess objective environmental conditions (terrestrial and aquatic) and specific features of blue infrastructure at each site. The BEAT will be used at least twice in the environmental interventions to document change before and after their implementation. The tool includes evaluation of water quality, accessibility, litter and vandalism, signage, and so on.

3. The BlueHealth SoftGIS (BSGIS) tool will use participatory mapping ${ }^{84}$ to understand how local residents use the blue spaces in the cities under study. One limitation of all pre-post intervention work is knowing whether changes are site-related or reflect more general changes in attitudes and behaviours. Enabling local residents to comment on their experiences in local blue spaces will provide a more rounded picture of the importance and relevance of changes made at these sites.

4. The BlueHealth Behavioural Assessment Tool (BBAT) will be used to systematically observe and record how people behave and interact in different areas at relevant CLI sites. Observations made pre-intervention and post-intervention provide information on how behaviour has changed as a result, and inform us about any affordances generated for specific user groups.

5. The BlueHealth Physiological Assessment Tool (BPAT) will be used in the Thessaloniki and Barcelona behavioural interventions (and adapted for use in VR studies). A variety of physiological measures will be collected from participants pre-intervention and post-intervention to investigate short-term effects of spending time in and around blue space on stress and well-being.

\section{Virtual reality}

BlueHealth will employ innovative VR technology in two distinct ways. First, we will create computer-generated imagery of each urban acupuncture site for use by planners and stakeholders in order to optimise the intervention prior to implementation. Using VR with stakeholders in the design phase provides the opportunity to obtain a realistic impression of the proposed intervention, allowing better informed discussion. Second, we aim to deliver health and well-being benefits of blue space to individuals unable to access outdoor environments, either because they are undergoing medical treatment or because they are prevented from visiting blue space due to age, ill health, disability or environmental conditions. This will require research that builds on the current evidence. ${ }^{428586}$ We will further investigate the efficacy of VR blue spaces in the reduction of stress and discomfort during medical procedures such as dental treatment. ${ }^{85} 87$ In parallel, we will examine how interactive VR technology and/or the ability to choose visit locations can be used in residential care settings to enable older people to, for instance, 'visit' blue space locations of their own choosing more frequently.

The VR environments and in situ protocols will be developed in collaboration with stakeholders and user groups to ensure desirability and feasibility. Piloting and testing, within controlled laboratory settings, will be conducted prior to in situ testing to investigate the psycho-biological pathways between virtual blue space exposure and health and well-being outcomes in key target groups. ${ }^{88}$ Such work will enable us to explore the underlying mechanisms that are often hard to demonstrate in real-world settings.

\section{Informing urban planning policy and long-term strategy}

The BlueHealth evidence base will provide information on how changes to urban blue infrastructure and societal behaviours can maximise benefits to health and wellbeing associated with blue space. In order to best inform planning over a longer timescale-and to identify optimal blue infrastructure intervention strategies-a number of ideal-typical visions of the future (2050) will be elaborated based on plausible and health-relevant changes in demographic, economic, societal, technological, ecological and political spheres. ${ }^{89}$ Five such BlueHealth Futures will be designed to explore the potential ramifications of rapidly changing environments and climate in 
the context of social and environmental inequalities and demographic change which are particularly pertinent to the health benefits and risks of interactions with urban blue infrastructure (eg, flooding, water quality, urban heat islands), and to evaluate the effects of adaptive strategies. For this purpose, environmental and societal trends on global, European and national levels will be scaled down to the city level. Having identified the future developments that will most significantly affect public health, the BlueHealth Futures can be used to identify promising policy options and strategies for influencing them. This will be done with identified intersector stakeholders from government, business, academia and citizen organisations.

Finally, a BlueHealth decision support tool (DST) will be developed with ongoing stakeholder input and engagement. Building on similar DSTs on urban green infrastructure, the BlueHealth DST will provide policymakers with a novel means approach planning of blue infrastructure-in the face of climate and other environmental change-with both health promotion and the management of potential health risks in mind.

\section{DISCUSSION}

The principal aim of the BlueHealth project is to quantify the impacts on population health and well-being of existing and novel environmental interventions (as well as individual-level behavioural initiatives) connected to blue space environments, and to identify the opportunities and obstacles for efficient policymaking and cross-sectoral collaboration in this area.

Assessments of the health and well-being (and environmental) co-benefits, risks, trade-offs and costs will improve our understanding of the role of urban blue infrastructures in cross-sector health promotion and disease prevention. Many of these infrastructures were originally designed for other policy goals (eg, transport, flood prevention). However, innovative design and planning can promote health by ensuring that the co-benefits are captured and governance processes should be designed with this broader perspective in mind. For example, given people's preferences for blue spaces and their willingness to visit them, ${ }^{3890}$ the evidence suggests that the population uptake of blue infrastructure initiatives that encourage, for instance, greater levels of active recreation, will be particularly high, and thus important for disease prevention and health promotion. The precise conditions of governance needed for such initiatives to be effective are as yet unclear.

We anticipate that the design of this intersectoral, international and multidisciplinary BlueHealth project, and of the research programme laid out in this article, will provide key evidence to those making decisions on the development and maintenance of Europe's urban blue infrastructures on how to maximise the public health benefits of their policies and projects, to minimise health inequalities across and within populations, and to prepare for future changes in demography and climate. In addition to the evidence base, BlueHealth will produce a number of tools, suitable and available, for incorporation into design, planning and evaluation of interventions and governance processes conducted in, on and around urban blue infrastructure. The legacy of the projectdata, evidence, interventions, tools, recommendations and networks of experts and other stakeholders-will result in decision-making and urban planning that better integrates public health and disease prevention strategies. Given the sizeable investments needed to protect cities against climate change-particularly those on or near blue space-in coming years, we anticipate that this intersectoral and co-benefit integration could potentially generate large returns in terms of improved population health.

Depending on how the BlueHealth DST is developedwhich will in large part be based on stakeholder needs identified-this tool could be applied to assess the public health impact of various scenarios concerning changes in infrastructure, climate or other drivers. Considered application of such a tool might be useful in the targeted planning of blue space infrastructure to minimise health inequalities in areas characterised by particular vulnerabilities, including assessing the transformability potential of aspects of urban environments.

The BlueHealth project is chiefly aimed at the better understanding the benefits to health and well-being of non-occupational interaction with blue space in urban settings. Health risks related to recreation or working in environments with water are assessed, but not investigated explicitly in the BlueHealth project. Several occupations are specific to such environments, and many of these present specific risks (eg, commercial fishing is one of the most hazardous professions globally ${ }^{91-93}$ ). Since these risks are well understood (compared with the benefits), the BlueHealth project will devote less time to these issues, principally drawing on the existing evidence base on risk when developing the DST, for example.

The pan-European focus of BlueHealth will generate information primarily of relevance to decision-makers across Europe and high-income countries. We are currently uncertain about how the outputs from BlueHealth will transfer to low-and-middle-income countries, in part due to the pace and nature of urban development in these regions, and in part due to the potentially greater risks associated with waterborne disease and other exposures. The concept, and several of the methods, of the BlueHealth project could, however, be readily transferable to other geopolitical contexts. The rapid urban development taking place across the globe requires the construction of urban blue infrastructure on a substantial scale to meet the demands of various sectors. Better understanding of both the risks and benefits associated with this blue infrastructure through a set of developing world case studies might serve to incorporate non-traditional health promotion and disease prevention into 
development strategies in the fast-growing megapolises of low-and-middle-income countries.

Historically, physical mechanisms have been popularly described as the means by which blue environmentsin particular the sea-positively influence health, for example, invigoration of the body and mind through contact with 'bracing sea air'. Although there is little evidence of these effects, a number of hypothetical biochemical mechanisms have been put forward, including exposures to low levels of airborne microbiota and biogenic products (including phytochemical and particulate allergens), some of which may interact with inflammatory cell signalling pathways to benefit human health. ${ }^{94}$ The empirical evidence for such mechanisms is relatively limited, and there are currently no plans to investigate these issues in detail with the scope of BlueHealth. Rather, this project has purposely been focused on those recreational, cultural and ecosystem services interactions with the blue environment to which we expect the majority of health benefits might be attributed.

\section{Author affiliations}

${ }^{1}$ European Centre for Environment and Human Health (ECEHH), University of Exeter Medical School, Truro, UK

${ }^{2}$ Faculty of Medicine, School of Public Health, Imperial College, London, UK ${ }^{3}$ Psychology Applied to Health (PAtH), University of Exeter Medical School, Exeter, UK ${ }^{4}$ Occupational and Environmental Medicine (OEM), Department of Laboratory Medicine, University of Lund, Lund, Sweden

${ }^{5}$ Institute of Environmental Medicine (IMM), Karolinska Institute, Stockholm, Sweden ${ }^{6}$ Department of Landscape Architecture, Estonian University of Life Sciences, Tartu, Estonia

${ }^{7}$ OPENspace, Edinburgh College of Art, University of Edinburgh, Edinburgh, Scotland ${ }^{8}$ Centre for International Health Research (CRESIB), Instituto de Salud Global de Barcelona (ISGlobal), Hospital Clínic, Universitat de Barcelona, Barcelona, Spain ${ }^{9}$ Centre for Research in Environmental Epidemiology (CREAL), Instituto de Salud Global de Barcelona (ISGlobal), Barcelona, Spain

${ }^{10}$ Universitat Pompeu Fabra (UPF), Barcelona, Spain

${ }^{11}$ CIBER Epidemiología y Salud Pública (CIBERESP), Barcelona, Spain

${ }^{12}$ Fondazione Centro Euro-Mediterraneo sui Cambiamenti Climatici (CMCC), Bologna, Italy

${ }^{13}$ Istituto Superiore di Sanità (ISS), Rome, Italy

${ }^{14}$ Aristotle University of Thessaloniki (AUTH), Thessaloniki, Greece

${ }^{15}$ Department of Forest and Conservation Sciences, Faculty of Forestry, University of British Columbia, Vancouver, BC, Canada

${ }^{16}$ WHO European Centre for Environment and Health, WHO Regional Office for Europe, Bonn, Germany

${ }^{17}$ School of Population and Public Health, Faculty of Medicine, University of British Columbia, Vancouver, BC, Canada

${ }^{18}$ National Institute for Public Health and the Environment (RIVM), Bilthoven, The Netherlands

Correction notice This paper has been amended since it was published Online First. Owing to a scripting error, some of the publisher names in the references were replaced with 'BMJ Publishing Group'. This only affected the full text version, not the PDF. We have since corrected these errors and the correct publishers have been inserted into the references.

Contributors JG, MPW, LEF and LRE drafted this manuscript on the basis of a grant proposal which was devised and written by MPW, LEF, MA, SB, MG, SG, LM MJN, DAS, MvdB, TW and SW. All of the authors made substantial contributions to the Methods section of the draft manuscript, in which the conception and design of aspects of the work for which they are responsible in the BlueHealth project are described. Specifically: JG, LRE and MPW constructed the BlueHealth Conceptual Model; JG, LRE, MPW, MA, MG and MJN wrote the sections on Reviews and Secondary data analysis; JG, LRE, MPW, SB, MG, SG, LM, MJN and MvdB wrote sections on Primary data collection and analysis; and TW, SW and DAS rewrote the section on Informing urban planning policy and long-term strategy. All coauthors also contributed to the writing of the Introduction and Discussion sections. JG subsequently prepared a final version of the manuscript based on co-author contributions. All authors then read the final version, approved it for submission for publication and agree to be accountable for all aspects of the work.

Funding This work was supported by funding received from the European Union's Horizon 2020 research and innovation programme under grant agreement no. 666773.

Competing interests All authors report grants from European Union Horizon 2020 programme (grant number 666773), during the conduct of the study.

Patient consent The research being conducted does not involve patients. As explained above, all work carried out within this programme of research that involves human subjects is reviewed by, and subject to approval from, relevant local ethics committees. Where applicable, informed consent will be obtained from study participants. All results from work that is conducted in this project involving human subjects will be anonymised and all relevant safeguards have been put in place to ensure that complete anonymity of all participants is preserved.

Ethics approval Throughout the BlueHealth project, ethics review and approval are obtained for all aspects of the study by the relevant local ethics committees before any work is conducted. Stakeholder engagement also involves citizens in many aspects of the project throughout.

Provenance and peer review Not commissioned; externally peer reviewed.

Open Access This is an Open Access article distributed in accordance with the Creative Commons Attribution Non Commercial (CC BY-NC 4.0) license, which permits others to distribute, remix, adapt, build upon this work non-commercially, and license their derivative works on different terms, provided the original work is properly cited and the use is non-commercial. See: http://creativecommons.org/ licenses/by-nc/4.0/

(c) Article author(s) (or their employer(s) unless otherwise stated in the text of the article) 2017. All rights reserved. No commercial use is permitted unless otherwise expressly granted.

\section{REFERENCES}

1. Solomon S. Water: the epic struggle for wealth, power, and civilization. New York: Harper Collins, 2011.

2. Neumann B, Vafeidis AT, Zimmermann J, et al. Future coastal population growth and exposure to sea-level rise and coastal flooding--a global assessment. PLoS One 2015;10:e0118571.

3. The WaRe project. Case study: Bratislava. 2016 http://www.chaplin. ee/english/ware/index2a9c.html?option=com_content\&view=article\& $i d=28 \&$ Itemid=54 (accessed 8 Nov2016).

4. Gomez MV. Reflective images: the case of urban regeneration in Glasgow and Bilbao. Int J Urban Reg Res 1998;22:106-21.

5. Doucet B. Rich cities with poor people waterfront regeneration in the Netherlands and Scotland. Utrecht, Netherlands: Netherlands Geographical Studies, 2010.

6. London Docklands Development Corporation. LDDC's Regeneration Statement 1998 http://www.lddc-history.org.uk/regenstat/ (accessed 8 Nov2016).

7. Schafer B. Docklands project: Melbourne Australia. Melbourne, Australia: BLS Consulting, 2015.

8. Brownill S, O'Hara G. From planning to opportunism? Re-examining the creation of the London Docklands Development Corporation. Plan Perspect 2015;30:537-70.

9. Wang C. Waterfront regeneration. 2002:1-24.

10. Hoyle B. Fields of tension: development dynamics at the port-city interface. Jew Cult Hist 2001;4:12-30.

11. Mah A. Port cities and global legacies: urban identity, waterfront work, and radicalism. Basingstoke, UK: Palgrave MacMillan, 2014.

12. Feldman M. Urban waterfront regeneration and local governance in Tallinn. Eur Asia Stud 2000;52:829-50.

13. Couch C. Urban regeneration in Europe. Oxford, UK: Blackwell Science, 2003.

14. Gospodini A. Urban waterfront redevelopment in greek cities: a framework for redesigning space. Cities 2001;18:285-95.

15. Jauhiainen JS. Waterfront redevelopment and urban policy: the case of Barcelona, Cardiff and Genoa. European Planning Studies 1995;3:3-23. 
16. Bezmez D. The politics of urban waterfront regeneration: the case of Haliç (the Golden Horn), Istanbul. Int J Urban Reg Res 2008;32:815-40.

17. Jones $A$. Issues in waterfront regeneration: more sobering thoughts-A UK perspective. Plan Prac Res 1998;13:433-42.

18. Sairinen $R$, Kumpulainen $S$. Assessing social impacts in urban waterfront regeneration. Environ Impact Assess Rev 2006;26:120-35.

19. de Vries S, Verheij RA, Groenewegen PP, et al. Natural environments - healthy environments? an exploratory analysis of the relationship between greenspace and health. Environment and Planning A 2003;35:1717-31.

20. Völker S, Kistemann T. The impact of blue space on human health and well-being-Salutogenetic health effects of inland surface waters: a review. Int J Hyg Environ Health 2011;214:449-60.

21. Wheeler BW, White M, Stahl-Timmins W, et al. Does living by the coast improve health and wellbeing? Health Place 2012;18:1198-201.

22. Miller D, Roe J, Brown C, et al. Blue health: water, health and wellbeing. Aberdeen 2012 www.crew.ac.uk/publications

23. WHO. Urban green spaces and health. Denmark: Copenhagen, 2016

24. Hopp MJ, Foley JA. Global-scale relationships between climate and the dengue fever vector, aedes aegypti. Clim Change 2001;48:441-63.

25. Hunter PR. Climate change and waterborne and vector-borne disease. J Appl Microbiol 2003;94 Suppl:37-46.

26. Keiser J, Utzinger J, Caldas de Castro M, et al. Urbanization in subsaharan Africa and implication for malaria control. Am J Trop Med Hyg 2004;71:118-27.

27. Ali M, Lopez AL, You YA, et al. The global burden of cholera. Bull World Health Organ 2012;90:209-18.

28. Crump JA, Mintz ED. Global trends in typhoid and paratyphoid fever. Clin Infect Dis 2010;50:241-6.

29. Villanueva CM, Kogevinas M, Cordier S, et al. Assessing exposure and health consequences of chemicals in drinking water: current state of knowledge and research needs. Environ Health Perspect 2014;122:213-21.

30. World Health Organization. Global report on drowning: preventing a leading killer. Geneva, CH, 2014. http://www.who.int/violence_injury_ prevention/global_report_drowning/en/.

31. Du W, FitzGerald GJ, Clark M, et al. Health impacts of floods. Prehosp Disaster Med 2010;25:265-72.

32. Alderman K, Turner LR, Tong S. Floods and human health: a systematic review. Environ Int 2012;47:37-47.

33. Hajat $\mathrm{S}$, Ebi KL, Kovats RS, et al. The human health consequences of flooding in Europe: A review. In: Kirch W, Bertollini R, Menne B, eds. Extreme Weather events and Public Health responses. Berlin: Springer Berlin Heidelberg, 2005:185-96.

34. Rosso S, Zanetti R, Martinez C, et al. The multicentre south european study 'Helios'. II: Different sun exposure patterns in the aetiology of basal cell and squamous cell carcinomas of the skin. Br J Cancer 1996;73:1447-54 http://www.pubmedcentral.nih.gov/ articlerender.fcgi?artid=2074492\&tool=pmcentrez\&rendertype= abstract

35. Wheeler BW, Lovell R, Higgins SL, et al. Beyond greenspace: an ecological study of population general health and indicators of natural environment type and quality. Int J Health Geogr 2015;14:17.

36. Nutsford D, Pearson AL, Kingham S, et al. Residential exposure to visible blue space (but not green space) associated with lower psychological distress in a capital city. Health Place 2016;39:70-8.

37. de Vries S, ten Have M, van Dorsselaer S, et al. Local availability of green and blue space and prevalence of common mental disorders in the Netherlands. Brit J Psych Open 2016;2:366-72.

38. Völker S, Kistemann T. Reprint of: "I'm always entirely happy when I'm here!" Urban blue enhancing human health and well-being in Cologne and Düsseldorf, Germany. Soc Sci Med 2013;91:141-52.

39. White MP, Alcock I, Wheeler BW, et al. Coastal proximity, health and well-being: results from a longitudinal panel survey. Health Place 2013;23:97-103.

40. MacKerron G, Mourato S. Happiness is greater in natural environments. Global Environ Change 2013;23:992-1000.

41. White MP, Pahl S, Ashbullby K, et al. Feelings of restoration from recent nature visits. J Environ Psychol 2013;35:40-51.

42. Annerstedt $M$, Jönsson $P$, Wallergård $M$, et al. Inducing physiological stress recovery with sounds of nature in a virtual reality forest-results from a pilot study. Physiol Behav 2013;118:240-50.

43. Schipperijn J, Ekholm O, Stigsdotter UK, et al. Factors influencing the use of green space: results from a danish national representative survey. Landsc Urban Plan 2010;95:130-7.

44. White MP, Wheeler BW, Herbert S, et al. Coastal proximity and physical activity: is the coast an under-appreciated public health resource? Prev Med 2014;69:135-40.
45. Ashbullby KJ, Pahl S, Webley P, et al. The beach as a setting for families' health promotion: a qualitative study with parents and children living in coastal regions in Southwest England. Health Place 2013;23:138-47

46. White MP, Bell S, Elliott LR, et al. The health benefits of blue exercise in the UK. In: Barton J, Bragg R, Wood C, eds. Green exercise : linking nature, health and well-being. Abingdon, UK: Routledge, 2016:211.

47. Völker S, Baumeister H, Claßen T, et al. Evidence for the temperature-mitigating capacity of urban blue space-a health geographic perspective. Erdkunde 2013;67:355-71

48. Hajat S, Vardoulakis S, Heaviside $C$, et al. Climate change effects on human health: projections of temperature-related mortality for the UK during the 2020s, 2050s and 2080s. J Epidemiol Community Health 2014;68:641-8.

49. Bengston DN, Fletcher JO, Nelson KC. Public policies for managing urban growth and protecting open space: policy instruments and lessons learned in the United States. Landsc Urban Plan 2004;69:271-86.

50. Ward Thompson C, Activity WTC. Activity, exercise and the planning and design of outdoor spaces. J Environ Psychol 2013;34:79-96.

51. Gillis K, Gatersleben B. A review of psychological literature on the health and wellbeing benefits of biophilic design. Buildings 2015;5:948-63.

52. Health WHO. A european policy framework and strategy for the 21 st century. Bonn 2020;2013.

53. Global Burden of Disease Study 2013 Collaborators. Global, regional and national incidence, prevalence, and years lived with disability for 301 acute and chronic diseases and injuries in 188 countries, 19902013: a systematic analysis for the global burden of disease study 2013. Lancet 2015;386:743-800.

54. McMichael AJ. Globalization, climate change, and human health. $N$ Engl J Med 2013;368:1335-43.

55. Nieuwenhuijsen MJ, Kruize H, Gidlow C, et al. Positive health effects of the natural outdoor environment in typical populations in different regions in Europe (PHENOTYPE): a study programme protocol. BMJ Open 2014;4:e004951.

56. Triguero-Mas M, Dadvand P, Cirach M, et al. Natural outdoor environments and mental and physical health: relationships and mechanisms. Environ Int 2015;77:35-41.

57. Pretty J. Health Values from Ecosystems. UK national ecosystem assessment: technical report. Cambridge, UK: WCMC-UNEP, 2011:1-48.

58. Lachowycz K, Jones AP. Towards a better understanding of the relationship between greenspace and health: development of a theoretical framework. Landsc Urban Plan 2013;118:62-9.

59. Keniger LE, Gaston KJ, Irvine KN, et al. What are the benefits of interacting with nature? Int J Environ Res Public Health 2013;10:913-35

60. Church A, Fish R, Haines-Young R, et al. UK national ecosystem assessment follow-on phase work package report 5: oultural ecosystem services and indicators. 2014 http://uknea.unep-wcmc. org/LinkClick.aspx?fileticket=10\%2FZhq\%2Bgwtc\%3D\&tabid=82.

61. Hartig T, Mitchell R, de Vries S, et al. Nature and health. Annu Rev Public Health 2014;35:207-28.

62. Korpela KM, Ylén M, Tyrväinen L, et al. Favorite green, waterside and urban environments, restorative experiences and perceived health in Finland. Health Promot Int 2010;25:200-9.

63. Völker S, Kistemann T. Developing the urban blue: comparative health responses to blue and green urban open spaces in Germany. Health Place 2015;35:196-205.

64. European Commission. Communication from the Commission to the European Parliament, the Council, the European Economic and Social Committee and the Committee of the Regions. Blue Growth: opportunities for marine and maritime sustainable growth 2012;12.

65. Bratman GN, Hamilton JP, Daily GC. The impacts of nature experience on human cognitive function and mental health. Ann N Y Acad Sci 2012;1249:118-36.

66. Capaldi CA, Dopko RL, Zelenski JM. The relationship between nature connectedness and happiness: a meta-analysis. Front Psychol 2014;5:1-15

67. Gascon M, Triguero-Mas M, Martínez D, et al. Mental health benefits of long-term exposure to residential green and blue spaces: a systematic review. Int J Environ Res Public Health 2015;12:4354-79.

68. McMahan EA, Estes D. The effect of contact with natural environments on positive and negative affect: a meta-analysis. $J$ Posit Psych 2015;9760:1-13.

69. Sandifer PA, Sutton-Grier AE, Ward BP. Exploring connections among nature, biodiversity, ecosystem services, and human health and well-being: opportunities to enhance health and biodiversity conservation. Ecosyst Serv 2015;12:1-15. 
70. Cracknell D, White MP, Pahl S, et al. Marine Biota and psychological Well-Being: a preliminary examination of Dose-Response Effects in an Aquarium Setting. Environ Behav 2015;28:1.

71. Goldberg DP, Williams Paul DPM. A user's guide to the general health questionnaire. Windsor, Berks: NFER-Nelson, 1988.

72. Ware JE, Sherbourne CD. The MOS 36-item short-form health survey (SF-36). I. Conceptual framework and item selection. Med Care 1992;30:473-83.

73. Cummins RA. The domains of life satisfaction: an attempt to order chaos. Soc Indic Res 1996;38:303-28.

74. Buck N, McFall S. Understanding society: design overview. Longit Life Course Stud 2012;3:5-17.

75. Generalitat De Catalunya Departament De Salut. Enquesta de salut de Catalunya Fitxa tècnica - Període 2010-2014. Barcelona, Spain 2012 http://salutweb.gencat.cat/web/.content/home/el_departament/ estadistiques_sanitaries/enquestes/02_enquesta_catalunya_ continua/documents/fitxatecnica_esca.pdf

76. Rosvall M, Grahn M, Modén B, et al. Hälsoförhållanden i Skåne Folkhälsoenkät Skåne 2008. Malmö 2008 http://www.skane.se/ umas/socmed

77. Copenhagen, Denmark: Urban Atlas2010. http://www.eea.europa.eu/ data-and-maps/data/urban-atlas\#tab-methodology

78. England N. Monitor of engagement with the Natural Environment. the national survey on people and the natural environment: technical Report from year 6 of the survey March 2014 to February 2015. London;2015 https://www.gov.uk/government/uploads/system/ uploads/attachment_data/file/481138/mene-technical-report-201415.pdf

79. Topp CW, Østergaard SD, Søndergaard S, et al. The WHO-5 well-being index: a systematic review of the literature. Psychother Psychosom 2015;84:167-76.

80. Survey ES. ESS7 - 2014 documentation report: the ESS data archive, Edition 3.0. Bergen, Norway: 2016 http://www.europeansocialsurvey. org/docs/round7/survey/ESS7_data_documentation_report_e03_0.pdf

81. White MP, Elliott LR, Taylor T, et al. Recreational physical activity in natural environments and implications for health: a population based cross-sectional study in England. Prev Med 2016;91:383-8.
82. Papathanasopoulou E, White MP, Hattam C, et al. Valuing the health benefits of physical activities in the marine environment and their importance for marine spatial planning. Mar Policy 2016;63:144-52.

83. Lerner J. Urban acupuncture. Washington DC: Island Press, 2014.

84. Kahila M, Kyttä M. SoftGIS as a Bridge-Builder in Collaborative Urban Planning. In: Geertman S, Stillwell JCH, eds. Planning support systems best practice and new methods. Dordrecht: Springer Netherlands, 2009:389-411. doi.

85. Tanja-Dijkstra K, Pahl S, White MP, et al. Improving dental experiences by using virtual reality distraction: a simulation study. PLoS One 2014;9:10.

86. Annerstedt M, Währborg P. Nature-assisted therapy: systematic review of controlled and observational studies. Scand J Public Health 2011;39:371-88.

87. Furman E, Jasinevicius TR, Bissada NF, et al. Virtual reality distraction for pain control during periodontal scaling and root planing procedures. J Am Dent Assoc 2009;140:1508-16.

88. White MP, Pahl S, Ashbullby KJ, et al. The effects of exercising in different natural environments on Psycho-Physiological outcomes in Post-Menopausal women: a simulation study. Int J Environ Res Public Health 2015;12:11929-53.

89. Behbod B, Lauriola P, Leonardi G, et al. Environmental and public health tracking to advance knowledge for planetary health. Euro $J$ Pub Heal 2016:ckw176.

90. White M, Smith A, Humphryes K, et al. Blue space: the importance of water for preference, affect, and restorativeness ratings of natural and built scenes. J Environ Psychol 2010;30:482-93.

91. Kaustell KO, Mattila TE, Rautiainen RH. Occupational injuries and diseases among commercial fishers in Finland 1996-2015. Int Marit Health 2016;67:163-70.

92. Frantzeskou E, Jensen OC, Linos A. Health status and occupational risk factors in greek small fisheries workers. Int Marit Health 2016;67:137-43.

93. Levin JL, Gilmore K, Wickman A, et al. Workplace safety interventions for commercial fishermen of the gulf. J Agromedicine 2016;21:178-89.

94. Moore MN. More than just a breath of fresh air-why is being in the country good for us? Perhaps because it's slightly poisonous. New Sci 2015;226:26-7. 